\title{
In vitro antimicrobial efficacy of a fixed-dose combination of RHZE against $M$. tuberculosis
}

\author{
Vanessa Albertina Agertt, Pauline Cordenonsi Bonez, Caren Rigon Mizdal, Grazielle Guidolin \\ Rossi, Vanessa da Costa Flores, Marli Matiko Anraku de Campos*
}

\author{
Department of Clinical and Toxicological Analysis, Federal University of Santa Maria,
} Santa Maria, RS, Brazil

\begin{abstract}
The use of drugs in fixed-dose combination (FDC) is now recommended by the World Health Organization (WHO) due to the emergence of multidrug-resistant strains of Mycobacterium tuberculosis. FDC uses different drugs against tuberculosis (TB) in a single tablet for phase-intensive therapeutic intervention. This therapy aims to optimize treatment, to prevent inappropriate use of drugs, and to prevent the emergence of new resistant strains. This study aims to evaluate the susceptibility of clinical isolates of M. tuberculosis against rifampicin, isoniazid, ethambutol, and pyrazinamide. The antimicrobials were tested separately and in associations according to FDC. This was used for broth microdilution method, which was compared to the proportions method previously considered as the gold standard. In antimicrobials testing alone, several strains were resistant to one, two, or three drugs. However, when applied to association of drugs in FDC, there was no antimicrobial resistance. The results strengthen the FDC's concept, which aims to unite the four anti-TB drugs to combat bacterial resistance.
\end{abstract}

Uniterms: Mycobacterium tuberculosis/treatment/drug combination. Mycobacterium tuberculosis/drug resistance. Mycobacterium tuberculosis/susceptibility/fixed dose combination.

\section{INTRODUCTION}

Defined as an infectious disease of the lungs, tuberculosis (TB) is caused by Mycobacterium tuberculosis. The World Health Organization (WHO) estimates that, in 2014, there was an incidence of 9.6 millions of new cases of tuberculosis worldwide. During this period, around 1.1 million people died of TB (WHO, 2015).

There is an increase in the incidence of multiresistant strains of $M$. tuberculosis, which may be caused, among other factors, by the lack of patient adherence to TB treatment, as this is extensive and may cause relevant side effects (Mitchison, Davies, 2012). The clinical impact of this resistance is immense, being characterized by an increase in treatment costs as well as an increase in morbidity and mortality (Lee et al., 2009). The inappropriate use of conventional antimicrobials for the treatment of microbial infections has contributed to the

\footnotetext{
*Correspondence: M. M. A. de Campos. Universidade Federal de Santa Maria - UFSM. Avenida Roraima, 1000 Roraima - 97105-900 - Santa Maria - RS, Brazil. E-mail: marlimatiko@yahoo.com
}

increase of rates of resistance (Mitchison, Davies, 2012).

TB control measures, such as vaccination with BCG (Bacillus Calmette-Guérin) and chemoprophylaxis, appear to be unsatisfactory. The role of BCG vaccination is just to provide a degree of protection against severe forms of TB. Thus, the key to the control of the infection is the rapid diagnosis and cure of patients infected (Campbell, Bah-Sow, 2006).

TB can usually be treated with a standard course of four drugs, rifampicin $(\mathrm{R})$, isoniazid $(\mathrm{H})$, pyrazinamide $(Z)$, and ethambutol (E), also known as first-line antituberculosis drugs (Mitnikc, McGee, Peloquin, 2009). Currently, several authors have reported synthetic or natural substances that are able to inhibit the growth of M. tuberculosis, but more studies are needed so that they become a viable alternative in the treatment of patients (Agertt et al., 2012; Boligon et al., 2012; Gising et al., Nielsen et al., 2012; Pucci et al., 2010; Vilchèze et al., 2011). Further clinical trials, probably not complete studies on new drugs against TB in the next 10 years, are urgently needed for the rational and adequate use of rifampicin and isoniazid once its use as monotherapy induces primary resistance (Hall, Leff, Gumbo, 2009). 
To prevent multidrug resistance, WHO recommends the use of a fixed-dose combination (FDC) of drugs for the treatment of TB (Blomberg et al., 2001). FDCs are formulations containing two or more antituberculosis drugs combined in a single tablet. At the stage of intensive care, the tablet contains $150 \mathrm{mg}$ of rifampicin, $75 \mathrm{mg}$ of isoniazid, $400 \mathrm{mg}$ of ethambutol, and $275 \mathrm{mg}$ of pyrazinamide. The maintenance phase consists of one tablet composed of $150 \mathrm{mg}$ of rifampicin and $75 \mathrm{mg}$ of isoniazid (Blomberg, Fourie, 2003).

While preventing the monotherapy and facilitating the ingestion of appropriate doses of antituberculosis drugs, it is expected that FDC helps prevent the emergence of antimicrobial resistance. Other advantages of the implementation of FDC are: simplification of treatment, reduction of medication prescribing errors, improved patient adherence to treatment, reduced treatment supervision, management simplification in the supply of drugs, calculated drug needs, as well as ensuring the availability of high-quality drugs and delivery of the correct dose of all drugs to the patient. In addition, FDC does not produce more adverse effects than the equivalent combinations of drugs formulated separately (Blomberg, Fourie, 2003).

Due to the high incidence of TB and the emergence of resistant strains, monitoring and evaluation of the susceptibility profile of the antituberculosis drugs in clinical isolates are necessary measures to control tuberculosis. Moreover, a better understanding of bacterial behavior in relation to drug therapies currently applied in patients with active TB can assist in the therapeutic effectiveness and success of the treatment.

\section{MATERIALS AND METHODS}

The bacilli isolated from patients with tuberculosis were from the Clinical Laboratory of the University Hospital of Santa Maria - LAC-HUSM, which receives patients from throughout Central Southern Brazil in the period from January to December 2010 . We analyzed the cultures of the samples collected from patients with suspected tuberculosis who obtained positive smear and culture, as directed by the Manual for Tuberculosis Bacteriology (BRASIL, 2005).

A small portion of the positive cultures was removed for re-plating and isolation in Lowenstein-Jensen (LJ). Tests were performed to differentiate between nontuberculous mycobacteria and bacteria probably belonging to the $M$. tuberculosis complex directed by the Manual for Tuberculosis Bacteriology (BRASIL, 2005).

After the samples were classified by phenotypic and biochemical tests as belonging to the M. tuberculosis, identification was confirmed using molecular techniques. The samples were examined for the presence of IS6110 insertion by the polymerase chain reaction as described by Eisenach et al. (1990).

The 42 crops confirmed by molecular technique as M. tuberculosis and standard strain H37Rv were evaluated for susceptibility to antimicrobial agents $(\mathrm{R}, \mathrm{H}, \mathrm{E}, \mathrm{Z})$, according to the proportions method (PM) (Canetti et al., 1969) and the broth microdilution method (BMM). Subsequently, the microorganisms were tested against antimicrobial associated as a fixed-dose combination through the BMM.

Determination of the Minimum Inhibitory Concentration (MIC) of antimicrobials alone and in combination (R, H, Z, and E (Sigma $\left.{ }^{\circledR}\right)$ ) was performed by the adapted BMM (NCCLS, 2003; Franzblau et al., 1998; Syre, Ovrea, Grewal, 2010). Rifampicin was dissolved in methanol and other drugs in sterile ultrapure water as specified by the manufacturer. The primary dilutions were adjusted to the desired concentration in 7H9 Middlebrook medium base $\mathrm{pH}$ (6.6) supplemented with $10 \%$ OADC (oleic acid-albumin-dextrose-catalase) (Difco Laboratories, Detriot, Mich) and $0.2 \%$ glycerol (MD7H9). R and $\mathrm{H}$ were tested at concentrations of $0.25,0.5,1.0,2.0,4.0$, and 8.0 $\mathrm{mg} / \mathrm{mL}$, the $\mathrm{Z}$ concentrations of $25,50,100,200,400$ to 800 $\mathrm{mg} / \mathrm{mL}$, and $\mathrm{E}$ at concentrations of 4.0, 8.0, 16, 32, 64 to $128 \mathrm{mg} / \mathrm{mL}$. These four drugs were tested in combination, at the same concentrations in BMM; therefore, the concentration of each drug used in the tests was equal to the isolated drugs. The bacterial suspensions were prepared in $\mathrm{MD} 7 \mathrm{H} 9$ medium and incubated at $35^{\circ} \mathrm{C}$ for 7 days in tubes containing glass beads of $2-\mathrm{mm}$ diameter, for subsequent homogenization and dissolution on a vortex mixer. The bacterial suspension was adjusted to the MacFarland scale 1 and was then diluted 1/25 in MD7H9 at the time of use.

The BMM was performed on 96-well cell culture dishes. Colony growth was observed by the appearance of white dots without the use of dyes. Strains were considered resistant if they possessed the superior growth at concentrations of $1 \mu \mathrm{g} / \mathrm{mL}$ for $\mathrm{R}$ and $\mathrm{H}, 16 \mu \mathrm{g} / \mathrm{mL}$ for E, $100 \mu \mathrm{g} / \mathrm{mL}$ for $\mathrm{Z}$, and $1 / 1 / 16 / 100 \mu \mathrm{g} / \mathrm{mL}(\mathrm{R} / \mathrm{H} / \mathrm{E} / \mathrm{Z})$ for the association.

The study protocol was approved by the Ethics Committee of the Federal University of Santa Maria (UFSM) by CAAE number (Certificate presentation for Ethical Consideration) 0104.0.243.000-11.

\section{RESULTS}

Eighteen clinical isolates were resistant using the proportions method, including 10 resistant to one drug, 5 
resistant to two drugs, and 3 resistant to the three drugs. Figure 1 shows these proportions. Through microdilution method, 28 resistant isolates were found, including 16 resistant to one drug, 4 resistant to two drugs, and 8 resistant to the three drugs, which can be seen in Figure 2. The correlation between the methods is illustrated in Figure 3.

The isolates, when tested against four associated drugs, were considered all susceptible. Thirty-eight isolates showed an $\mathrm{MIC} \leq 0.25 / 0.25 / 4 / 25 \mu \mathrm{g} / \mathrm{mL}(\mathrm{R} / \mathrm{H} /$ $\mathrm{E} / \mathrm{Z}$ ), three showed MIC equal to $0.5 / 0.5 / 8 / 50 \mu \mathrm{g} / \mathrm{mL}$, and one isolate showed MIC equal to $1 / 1 / 16 / 100 \mu \mathrm{g} / \mathrm{mL}$

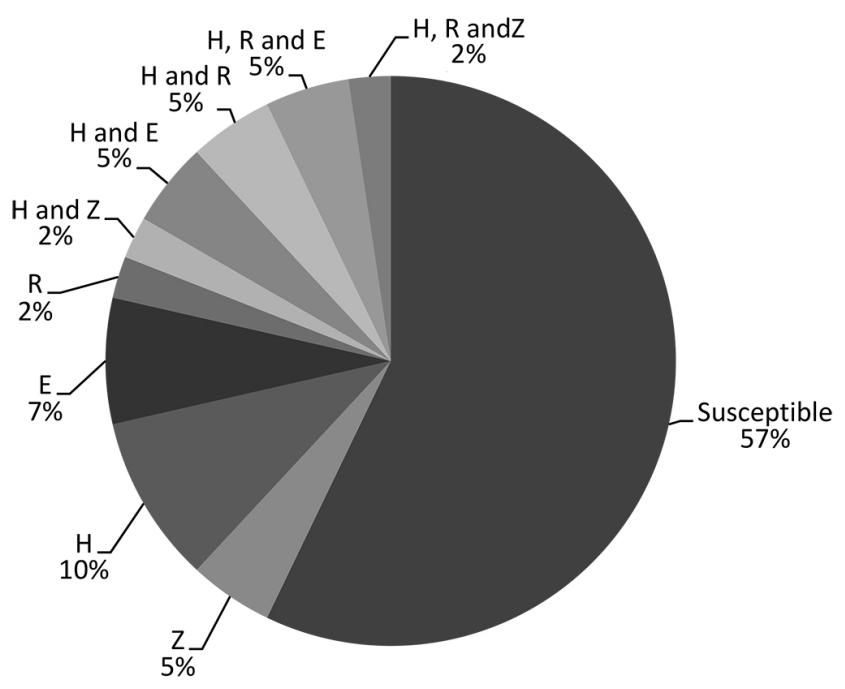

FIGURE 1 - Percentage of resistant strains by the proportions method. Rifampicin (R), isoniazid $(H)$, pyrazinamide $(Z)$, ethambutol (E).

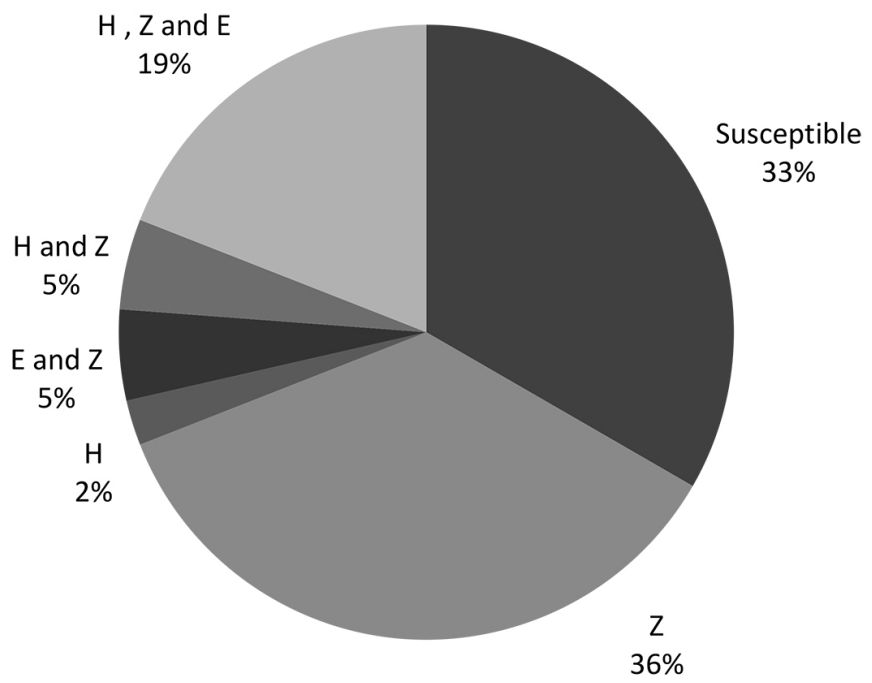

FIGURE 2 - Percentage of resistant strains by broth microdilution method. Isoniazid $(\mathrm{H})$, pyrazinamide $(\mathrm{Z})$, ethambutol $(\mathrm{E})$.
$(\mathrm{R} / \mathrm{H} / \mathrm{E} / \mathrm{Z})$. Among these four, three isolates were resistant to isoniazid, ethambutol, and pyrazinamide when tested alone at MMC.

\section{DISCUSSION}

The identification of clinical isolates belonging to the $M$. tuberculosis complex was satisfactory, because $100 \%$ of the isolates characterized by the classical method (LJ with PNB) were also positive for the IS6110 insertion. The M. tuberculosis complex is composed of M. bovis, M. microti, and M. africanum, the latter two being found at low frequency in Brazil (BRASIL, 2005). M. bovis requires more stringent conditions to grow in culture, such as the addition of sodium pyruvate to the LJ medium, therefore, the analyzed isolates can be M. tuberculosis, because the medium used for growth of the samples was $\mathrm{LJ}$, not enriched for M. bovis.

Susceptibility tests carried out in liquid media are more sensitive than those using solid media, as the techniques of solid media use only drug concentration, whereas the techniques of a liquid medium make it possible to use various concentrations, increasing the evaluation possibilities.

Six clinical isolates resistant to rifampicin were detected using the proportion method, however, they showed less MICs of $0.25 \mathrm{mg} / \mathrm{mL}$ by microdilution broth method (Figure 3A). This may be due to one-off losses of rifampicin activity when LJ medium was coagulated.

Seven strains were considered susceptible to isoniazid using broth microdilution method, but were resistant in the proportion method (Figure 3B). This is based on the fact that these strains were susceptible with an $\mathrm{MIC} \leq 0.25 \mu \mathrm{g} / \mathrm{mL}$, and the concentration used in the $\mathrm{LJ}$ medium was $0.2 \mu \mathrm{g} / \mathrm{mL}$ in the proportion method; the MIC values should be between 0.2 and $0.25 \mu \mathrm{g} / \mathrm{mL}$ in order for the isolates to be considered susceptible.

Four strains were considered susceptible to ethambutol in broth microdilution method, however, such resistance is present when measured using the proportions method (Figure 3C). This was probably due to the fact that the strains with MIC present a sensitivity $\leq 4 \mu \mathrm{g} /$ $\mathrm{mL}$, the concentration ratio of the method used in the $\mathrm{LJ}$ medium was $2 \mu \mathrm{g} / \mathrm{mL}$, and the MIC values were supposed to be between 2 and $4 \mu \mathrm{g} / \mathrm{mL}$. Thus, these isolates are considered susceptible.

Strains resistant to pyrazinamide were detected using broth microdilution method, which did not correspond with the proportion method (Figure 3D). This may have occurred because pyrazinamide has its great efficacy against microorganisms while at acidic $\mathrm{pH}$, 
A

Rifampicin

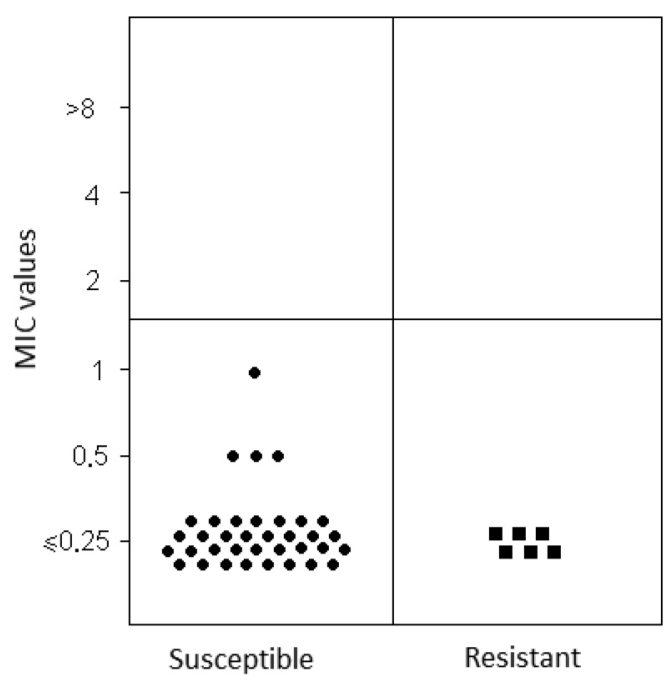

C

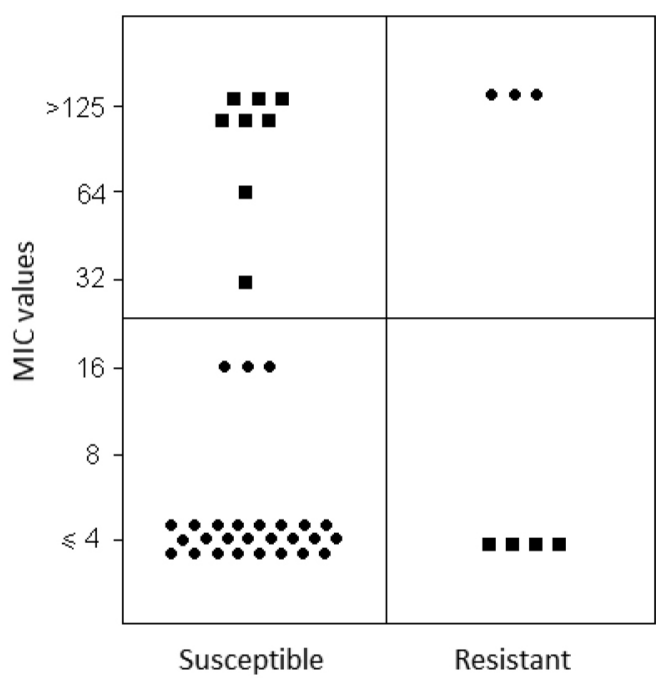

B

Isoniazid

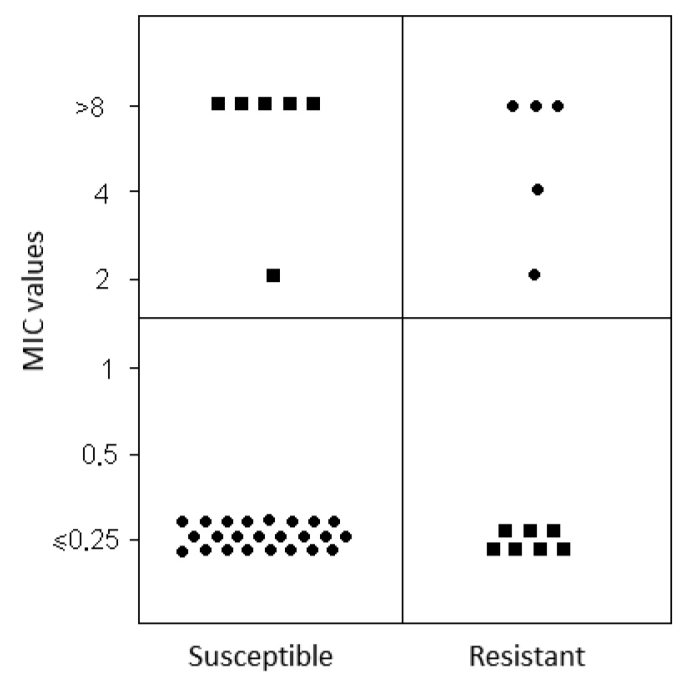

D

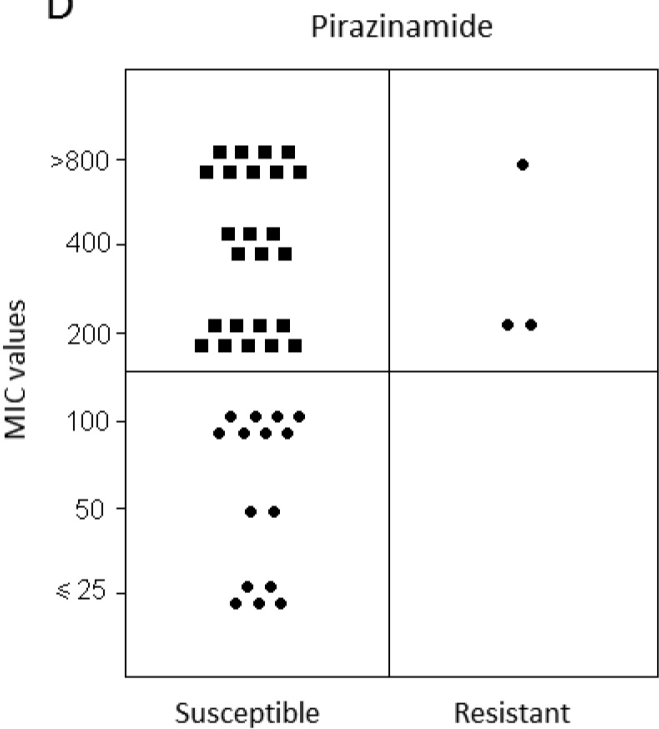

FIGURE 3 - Correlation between the MICs $(\mathrm{mg} / \mathrm{mL})$ found in the broth microdilution method and the proportions method classified to rifampicin (A), isoniazid (B), ethambutol (C), and pyrazinamide (D). $\bullet$ isolates that showed agreement between the methods. - isolates exhibiting disagreement among methods. The vertical lines separating isolates from the resistant and susceptible proportion method. The horizontal lines separating the susceptible and resistant isolates in the broth microdilution method.

which was not observed in broth microdilution method. This occurred because broth microdilution method was used as a reference that proves that a cutoff value of 100 $\mu \mathrm{g} / \mathrm{mL}$ of pyrazinamide revealed no changes in the results due to the pH (Syre, Ovrea, Grewal, 2010). Zhang, Zhang, Sun, (2003) proved that it is difficult for M. tuberculosis to maintain a neutral internal $\mathrm{pH}$ due to environmental conditions that cause an acidic $\mathrm{pH}$. The accumulation of weak acid could lead to the disruption of a proton-motive force, which is necessary for the transport of many nutrient substances to bacterial cells. However, weak acids that may be present in the inflammation process have an influence on the in vitro activity of pyrazinamide. The exposure for a short time of less than 3 to 5 days hardly shows any activity of pyrazinamide. This time, it is necessary to convert the prodrug pyrazinamide to pyrazinoic acid, which will act against the microorganism (Wade, Zhang, 2006). The in vitro testing for pyrazinamide still needs further studies to establish a better specificity of the methods, including the one conducted in this study which showed a value of falsepositive high when compared with the reference method.

Although various strains resistant to one, two, or three drugs were detected when tested separately by BMM, no strain was considered resistant when tested against four 
drugs associated by that method. This fact is in line with the concept of FDC, which united the four anti-TB drugs to combat the resistance of the bacilli. As studies have shown the bioequivalence between drugs of FDC (Agrawal et al., 2002), we showed in vitro that the use of FDC will combat the strains of $M$. tuberculosis resistant to first-line drugs used against TB.

According to Blomberg and Fourie (2003), to prevent monotherapy and facilitate the ingestion of appropriate doses of anti-TB drugs, it is expected that FDC will help prevent the emergence of drug resistance. With our study, we can say that FCD can fight resistant strains by not allowing more mutant bacilli emerge in the monotherapy.

The BMM proved to be a fast, easy to perform and well correlated with the PM, considered the gold standard for mycobacteria susceptibility methods, which can be used for epidemiological studies. A study involving a larger number of clinical isolates, and monitoring the treatment of infected patients would be of great epidemiological importance. This study then becomes a basis for further studies on the effectiveness in the treatment of tuberculosis.

\section{REFERENCES}

AGERTT, V.A.; MARQUES, L.L.; BONEZ, P.C.; DALMOLIN, T.V.; OLIVEIRA, G.N.M.; CAMPOS, M.M.A. Evaluation of antimycobacterial activity of a sulphonamide derivative. Tuberculosis, v.93, p.318-321, 2012.

AGRAWAL, S.; KAUR, K.J.; SINGH, I.; BHADE, R.S.; KAUL, C.L.; PANCHAGNULA, R. Assessment of bioequivalence of rifampicin, isoniazid and pyrazinamide in a four drug fixed dose combination with separate formulations at the same dose levels. Int. J. Pharm., v.233, p.169-177, 2002.

BLOMBERG, B.; FOURIE, B. Fixed-dose combination drugs for tuberculosis: application in standardised treatment regimens. Drugs, v.63, n.6, p.535-553, 2003.

BLOMBERG, B.; SPINACI, S.; FOURIE, B.; LAING, R. The rationale for recommending fixed-dose combination tablets for treatment of tuberculosis. B. W. Health Organ., v.79, p.61-68, 2001.

BOLIGON, A.A.; AGERTT, V.A.; JANOVIK, V.; CRUZ, R.C.; CAMPOS, M.M.A.; GUILLAUME, D.; ATHAYDE, M.L.; DOS SANTOS, A.R.S. Antimycobacterial activity of the fractions and compounds from Scutia buxifolia. Braz. J. Pharmacog., v.22, n.1, p.45-52, 2012.
BRASIL. MINISTÉRIO DA SAÚDE. Secretaria de Vigilância em Saúde. Centro de referencia Professor Hélio Fraga. Manual de Bacteriologia da Tuberculose. 3. ed. Rio de Janeiro, 2005.

CAMPBELL, I. A.; BAH-SOW, O. Pulmonary tuberculosis: diagnosis and treatment. Brit. Med. J., v.332, p.1194-1197, 2006.

CANETTI, G.; FOX, W.; KHOMENKO, A.; MAHLER, H.T.; MENON, N.K.; MITCHISON, D.A.; RIST, N.; SMELEV, N.A. Advances in techniques of testing mycobacterial drug sensitivity and the use of sensitivity tests in tuberculosis control programmes. Bull. WHO., v.41, p.31-43, 1969.

EISENACH, K.D.; CAVE, M.D.; BATES, J.H.; CRAWFORD, J.T. Polymerase chain reaction amplification of a repetitive DNA sequence specific for Mycobacterium tuberculosis. $J$. Infect. Dis., v.161, n.5, p.977-981, 1990.

FRANZBLAU, S.G.; WITZIG, R.S.; MCLAUGHLIN, J.C.; TORRES, P.; MADICO, G.; HERNANDEZ, A.; DEGNAN, M.T.; COOK, M.B.; QUENZER, V.K.; FERGUNSON, R.M.; GILMAN, R.H. Rapid low technology MIC determination with clinical Mycobacterium tuberculosis isolates by using the microplate alamar blue assay. $J$. Antimicrob. Chemother., v.36, n.2, p.362-366, 1998.

GISING, J.; NILSSON, M.T.; ODELL, L.R.; YAHIAOUI, S.; LINDH, M.; IYER, H.; SINHA, A.M.; SRINIVASA, R.; LARHED, M.; MOWBRA, Y.S.L.; KARLÉN, A. Trisubstituted imidazoles as Mycobacterium tuberculosis glutamine synthetase inhibitors. J. Med. Chem., v.55, p.2894-2898, 2012.

HALL, R.G.; LEFF, R.D.; GUMBO, T. Treatment of active pulmonary tuberculosis in adults: current standards and recent advances. Pharmacotherapy., v.29, n.12, p.14681481, 2009.

LEE, J.; CHOI, Y.; WOO, E.R.; LEE, D.G. Antibacterial and synergistic activity of isocryptomerin isolated from Selaginella tamariscana. J. Microbiol. Biotechnol., v.19, n.2, n.204-207, 2009.

MITCHISON, D.; DAVIES, G. The chemotherapy of tuberculosis: past, present and future. Int. J. Tuberc. Lung. D, v.16, n.6, p.724-732, 2012. 
MITNIKC, C.D.; MCGEE, B.; PELOQUIN, C.A. Tuberculosis pharmacotherapy: strategies to optimize patient care. Expert Opin. Pharmacol., v.10, n.3, p.381-401, 2009.

NATIONAL COMMITTEE FOR CLINICAL LABORATORY STANDARDS. NCCLS. Methods for dilution antimicrobial susceptibility tests for bacteria that grow aerobically: Approved standard. NCCLS document M7-A6. 6. ed. Wayne, PA: NCCLS, 2003.

NIELSEN, T.R.H.; KUETE, V.; JÄGER, A.K.; MEYER, J.J.M.; LALL, N. Antimicrobial activity of selected South African medicinal plants. BMC Complem. Altern. M., v.12, p.7478, 2012.

PUCCI, M.J.; ACKERMAN, M.; THANASSI, J.A.; SHOEN, C.M.; CYNAMON, M.H. In vitro antituberculosis activities of $\mathrm{ACH}-702$, a novel isothiazoloquinolone, against quinolone-susceptible and quinolone-resistant isolates. Antimicrob. Agents Chemother., v.54, n.8, p.3478-3480, 2010.

SYRE, H.; OVREA, K.; GREWAL, H.M.S. Determination of the susceptibility of Mycobacterium tuberculosis to pyrazinamide in liquid and solid media assessed by a colorimetric nitrate reductase assay. J. Antimicrob. Chemother, v.65, n.704-712, 2010.
VILCHÈZE, C.; BAUGHN, A.D.; TUFARIELLO, J.; LEUNG, L.W.; KUO, M.; BASLER, C.F.; ALLAND, D.; SACCHETTINI, J.C.; FREUNDLICH, J.S.; JACOBS, W.R. Novel inhibitors of InhA efficiently kill Mycobacterium tuberculosis under aerobic and anaerobic conditions. Antimicrob. Agents Chemother., v.55, n.8, p.3889-3898, 2011.

WADE, M.M.; ZHANG, Y. Effects of weak acids, UV and proton motive force inhibitors on pyrazinamide activity against Mycobacterium tuberculosis in vitro. J. Antimicrob. Chemother., v.58, p.936-941, 2006.

WORLD HEALTH ORGANIZATION. WHO. Global tuberculosis report 2015. Geneva: World Health Organization, 2015. $192 \mathrm{p}$.

ZHANG, Y.; ZHANG, H.; SUN, Z. Susceptibility of Mycobacterium tuberculosis to weak acids. J. Antimicrob. Chemother, v.52, p.56-60, 2003.

Received for publication on $07^{\text {th }}$ December 2015 Accepted for publication on $03^{\text {rd }}$ June 2016 